\title{
Manufacturing, Heat Treatment and Investigation of Foam-Filled Tubes
}

\author{
Domonkos Balázs KINCSES, 1,2,a Alexandra KEMÉNY,1,2,b Borbála LEVELES, 1,2,c \\ Dóra KÁROLY 1,2,d \\ ${ }^{1}$ Budapest University of Technology and Economics, Faculty of Mechanical Engineering, Department of \\ Materials Science and Engineering, Budapest, Hungary \\ ${ }^{2}$ MTA-BME Lendület Composite Metal Foams Research Group, Budapest, Hungary \\ a kincsesd@edu.bme.hu, ${ }^{b}$ alexa@eik.bme.hu, ${ }^{c}$ borbala.leveles@edu.bme.hu, ${ }^{d}$ kdora@eik.bme.hu
}

\begin{abstract}
Composite metal foams are hybrid structures with the main advantages of high specific strength and mechanical energy absorption associated with low density. In the course of our research, we successfully manufactured functional metal foams of EN AC-44200 matrix filled with lightweight expanded clay aggregate particles (LECAPs) in EN AW-6060 alloy tubes with a diameter of $50 \mathrm{~mm}$ and a wall thickness of $5 \mathrm{~mm}$. Manufacturing was performed by low-pressure infiltration directly into the aluminium tube. Six different types of samples were examined: metal matrix syntactic foam, in-situ metal foam, ex-situ metal foam, and their heat-treated pairs. In the compression tests, the heat treatment provided a visible improvement in the results of the ex-situ metal foams.
\end{abstract}

Keywords: functional metal foam, microstructural analysis, LECAP, heat treatment.

\section{Introduction}

As a structural material, knowledge of the manufacturability, strength, and failure process of composite metal foams are particularly important to ensure designability [1-3]. The main goals of this research are the production and development of various composite metal matrix syntactic foam-filled tubes and the mapping of mechanical properties with quasi-static compressive test. To achieve and fully understand the above, extensive microstructural and mechanical material tests were performed.

Metal matrix syntactic foams (MMSFs) are generally produced individually and not as functional, structural elements. Recent research has been conducted on foam-filled tubes (FFTs), mostly discussing aluminium-matrix foams placed in thinwalled tubes [4-8]. There have also been cases where MMSFs were surrounding thin-walled aluminium tubes [9], as well as in-situ FFTs prepared by powder compact foaming technique [10].

\section{Materials and methods}

\subsection{Materials}

In this research, EN AC-44200 matrix syntactic foams were filled into EN AW-6060 alloy tubes. Lightweight expanded clay aggregate (LECA) particles sold by Liapor GmbH \& Co. KG were used as fillers, which mainly contained $\mathrm{SiO}_{2}, \mathrm{Al}_{2} \mathrm{O}_{3}$ and $\mathrm{Fe}_{2} \mathrm{O}_{3}$ oxides. The internal structure of the particles gives the porosity of the produced metal foams

\subsection{Production}

For the tests, six different types of samples were prepared: in-situ FFTs, ex-situ FFTs, MMSFs and their heat-treated pairs (Table 1).

Table 1. Types and numbers of specimens

\begin{tabular}{|l|c|c|c|}
\hline & In-situ & Ex-situ & MMSF \\
\hline Non heat-treated (0) & 3 & 2 & 3 \\
\hline Heat-treated (T6) & 3 & 2 & $1^{*}$ \\
\hline
\end{tabular}

*The EN AC-44200 alloy does not respond to hardening. 
The in-situ foam-filled tubes were prepared by low-pressure infiltration, where the molten matrix material was poured directly into the EN AW-6060 tube filled with LECA particles. The infiltration parameters must be carefully adjusted, as the molten aluminium alloy may permeate the tube's wall.

The filler particles were first prepared for casting: LECA particles with an average diameter of Ø3.5-4 mm were mixed in a random close packing (RCP). These were placed into $\emptyset 50 \mathrm{~mm}$ outer and $\emptyset 40 \mathrm{~mm}$ inner diameter aluminium alloy (EN AW-6060) tubes. The tubes were welded at the bottom, with a hole drilled as a gas outlet. The bottom of the tube was padded with an alumina quilt to prevent the melt from flowing out, which was clamped with a stainless-steel net, and a stainless-steel net was also placed on top of the particles to prevent displacement and floating in the melt.

The particle-filled tubes were preheated in a furnace at $530{ }^{\circ} \mathrm{C}$ for 45 minutes. The EN AC- 44200 alloy was heated to an incandescent state in an induction melting furnace. After reaching a low viscosity molten state, the furnace was turned off, and the temperature of the melt was monitored with a digital thermometer while cooling. The EN AC-44200 alloy has a slightly higher melting point $\left(650^{\circ} \mathrm{C}\right)$ than the EN AC-44200 $\left(585^{\circ} \mathrm{C}\right)$, so the molten matrix can be poured poured between the particles, without melting through the tube wall. When the melt temperature reached $650{ }^{\circ} \mathrm{C}$, it was poured into the tube, and the Ar gas pressure required for infiltration was applied through an insulated pipe $(350 \mathrm{kPa})$. After cooling, the samples were cut into $40 \mathrm{~mm}$ tall pieces for compression tests. Their density was also measured.

MMSFs were manufactured similarly to foamfilled tubes, but a steel closed section was used instead of an aluminium tube. The samples were subsequently cut out into cylinders with a height of $40 \mathrm{~mm}$ and a diameter of $\emptyset 40 \mathrm{~mm}$. For the production of ex-situ metal foam-filled tubes, MMSFs machined to a given size $(\varnothing 40 \mathrm{~mm})$ were placed in empty tubes with a tight fit (Figure 1).

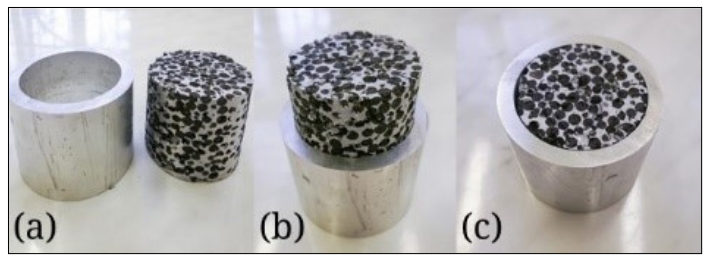

Figure 1. (a) Empty tube and MMSF, $(b, c)$ Placing MMSF in the tube.
In order to increase the strength of the aluminium alloys, heat treatment was performed on some samples since the base material of the tube (EN AW-6060) is precipitation hardenable.

During heat treatment, the $\mathrm{Mg}$ and Si are dissolved in the first step, and then diffusion is prevented by rapid cooling in water. During ageing, the compound precipitates from the supersaturated solid solution in a fine form and effectively increases the strength. The heat treatment steps were determined as heating at $300^{\circ} \mathrm{C} /$ hour and then holding at $500{ }^{\circ} \mathrm{C}$ for 2 hours. This is followed by rapid cooling in water. Then heating at $200^{\circ} \mathrm{C} /$ hour and keep at $200^{\circ} \mathrm{C}$ for 3 hours. Finally, rapid cooling in water.

\subsection{Measurements}

For microstructural examination of the manufactured metal foams, scanning electron microscopic (SEM) images were taken of the samples with a pre-polished surface.

The samples marked in Table 1 were tested using the ISO 13314:2011 standard to evaluate mechanical properties. Quasi-static compressive tests were performed on an Instron 5989 universal electromechanical material testing machine with a $600 \mathrm{kN}$ load cell and a Zwick / Roell Z400RED universal material testing machine with a $400 \mathrm{kN}$ load cell at a crosshead speed of $4 \mathrm{~mm} /$ min. A $0.3 \mathrm{~mm}$ thick Kolofol Teflon film was applied to the top and bottom of the specimens upon contact with the compression plates to reduce friction. For comparability, all specimens were compressed to at least $50 \%$ engineering strain.

From these data, the maximum of the compressive strength $\left(\sigma_{c}\right)$ and energy absorption $\left(\mathrm{W}_{50 \%}{ }^{-}\right.$ area under the curve) values were determined up to $50 \%$ engineering strain.

\section{Results}

SEM images show precipitates (white portions) of different sizes and distributions in both materials (Figure 2). It can be observed that there is no gap between the alloys, only a few minor scratches can be seen on the tube material. It can also be observed that the precipitates in both alloys are smaller in size and more densely distributed in the heat-treated sample.

Comparing the curves of the non-heat-treated specimens with the curves of the heat-treated specimens (Figure 3) it can be seen that the heat treatment had a significant effect on the properties of the ex-situ FFTs. The curve groups move together up to roughly $20 \%$ deformation and then 


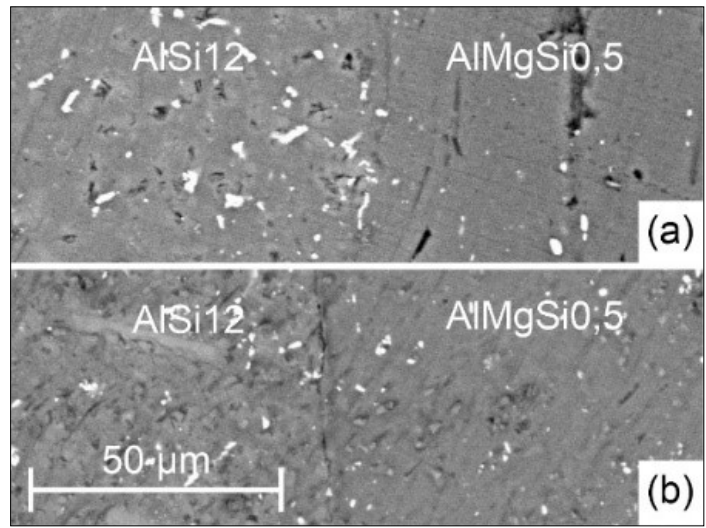

Figure 2. SEM images taken (a) before and (b) after heat treatment of an in-situ specimen

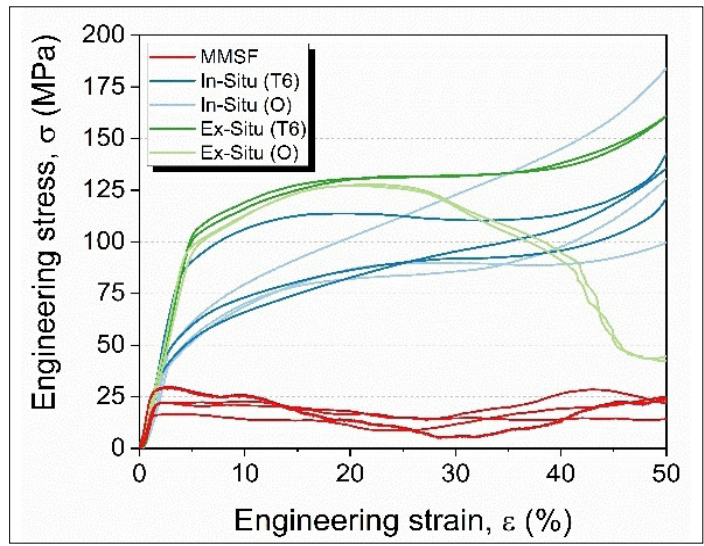

Figure 3. Stress-strain curves for each specimen.

split there. It can also be observed that the heat treatment did not affect the properties of the individual metal foams as expected.

It can also be seen that the properties of the in-situ FFTs were not significantly affected by the heat treatment process, except for the properties of one specimen. In the initial stage, the compressive force significantly exceeded the values of the non-heat treated in-situ FFTs, and the nature of its curve is similar to that of ex-situ heat-treated FFTs. One possible reason for this was that the other heat-treated specimens' cooling was not fast enough, requiring further testing.

It can be observed that while the values of ex-situ FFTs improved as a result of heat treatment, the same cannot be said about the in-situ FFTs. However, the standard deviation of the compressive strength of non-heat treated in-situ FFTs is large (Table 2)
Table 2. Results of the compressive test by specimen type

\begin{tabular}{|c|c|c|}
\hline & $\begin{array}{c}\text { Engineering } \\
\text { stress } \\
\sigma_{\mathrm{c}}(\mathrm{MPa})\end{array}$ & $\begin{array}{l}\text { Absorbed energy } \\
W_{50 \%}\left(\mathrm{~J} / \mathrm{cm}^{3}\right)\end{array}$ \\
\hline MMSF (O) & $24.75 \pm 4.52$ & $8.88 \pm 1.16$ \\
\hline MMSF (T6) & 12.19 & 7.47 \\
\hline In-situ (O) & $138.17 \pm 42.79$ & $45.33 \pm 8.62$ \\
\hline In-situ (T6) & $133.09 \pm 10.99$ & $46.13 \pm 6.25$ \\
\hline Ex-situ (O) & $127.45 \pm 0.43$ & $49.09 \pm 0.61$ \\
\hline Ex-situ (T6) & $159.47 \pm 1.93$ & $61.77 \pm 0.44$ \\
\hline
\end{tabular}

\section{Conclusions}

From the results obtained during our research, we came to the following conclusions:

- The production of in-situ aluminium foams infiltrated into an aluminium tube is not only possible but also simple and low-cost.

- The use of heat treatment is justified because:

- In the case of ex-situ FFTs, it greatly improves the properties of the material. The tube does not fall apart during compression, and thus the specific energy absorption of the foam increases significantly.

- With proper heat treatment, in-situ FFTs approach the values of ex-situ FFTs, which is important because in-situ FFTs can be produced in fewer steps, simpler, and faster.

- On the SEM images, it can be seen, that there is a tight fit between the tube and the foam and that finer precipitates appeared as a result of the heat treatment, causing an increase in strength, based on the compressive tests. An ex-situ procedure cannot achieve such a tight fit.

\section{Acknowledgements}

The publication of the work reported herein has been supported by the NTP-SZKOLL-20-0067 National Talent Programme of the Ministry of Human Capacities. The research reported in this paper and carried out at BME has been supported by the NRDI Fund (TKP2020 IES, Grant No. BME-IE-NAT; TKP2020 NC, Grant No. BME-NCS) based on the charter of bolster issued by the NRDI Office under the auspices of the Ministry for Innovation and Technology.

This work was supported in part by the Hungarian Scientific Research Fund under Grant agreement OTKA FK_21 138505 


\section{References}

[1] Orbulov I. N., Szlancsik A.: On the Mechanical Properties of Aluminum Matrix Syntactic Foams. Advanced Engineering Materials, 170098. (2018). doi.org/10.1002/adem.201700980

[2] Szlancsik A., Katona B., Dombóvári Z., Orbulov I. N.: On the effective Young's modulus of metal matrix syntactic foams. Materials Science and Technology, 33. (2017) 2283-2289.

doi.org/10.1080/02670836.2017.1374497

[3] Katona B., Orbulov I. N.: Structural damages in syntactic metal foams caused by monotone or cyclic compression. Periodica Polytechnica, 61/2. (2017) 146-152. doi.org/10.3311/PPme.10346

[4] Yang X., An T., Wu Z., Zou T., Song H., Sha J., He C., Zhao N.: The effect of outer tube on quasi-static compression behavior of aluminum foam-filled tubes. Composite Structures, 245:112357. (2020) doi.org/10.1016/j.compstruct.2020.112357

[5] Linul E., Movahedi N., Marsavina L.: The temperature effect on the axial quasi-static compressive behavior of ex-situ aluminum foam-filled tubes. Composite Structures, 180. (2017) 709-722. doi.org/10.1016/j.compstruct.2017.08.034

[6] Rajak D. K., Mahajan N. N., Linul E.: Crashworthiness performance and microstructural char- acteristics of foam-filled thin-walled tubes under diverse strain rate. Journal of Alloys and Compounds, 775. (2019) 675-689. doi.org/10.1016/j.jallcom.2018.10.160

[7] Zhang B., Wang L., Zhang J., Jiang Y., Wang W., Wu G.: Deformation and energy absorption properties of cenosphere/aluminum syntactic foamfilled circular tubes under lateral quasi-static compression. International Journal of Mechanical Sciences, 192:106126. (2021). doi.org/10.1016/j.ijmecsci.2020.106126

[8] Garai F., Béres G., Weltsch Z.: Development of tubes filled with aluminium foams for lightweight vehicle manufacturing. Materials Science \& Engineering A, 790:139743. (2020) doi.org/10.1016/j.msea.2020.139743

[9] Movahedi N., Murch G. E., Belova I. V., Fiedler T.: Manufacturing and compressive properties of tube-filled metal syntactic foams. Journal of Alloys and Compounds, 822:153465. (2020). doi.org/10.1016/j.jallcom.2019.153465

[10] Duarte I., Vesenjak M., Krstulović-Opara L., Ren Z.: Static and dynamic axial crush performance of in-situ foam-filled tubes. Composite Structures, 124. (2015) 128-139.

doi.org/10.1016/j.compstruct.2015.01.014 